\title{
Using Epoxy Resin as Partial Cement Replacement in Concrete with Silica Sand as Fine Aggregate
}

\author{
Gul Ahmed Jokhio ${ }^{1, *}$, Yasmeen Gul ${ }^{2}$, Abid Abu-Tair ${ }^{1}$ \\ ${ }^{1}$ Faculty of Engineering \& IT, The British University in Dubai, United Arab Emirates \\ ${ }^{2}$ College of Architecture and Design, Al Ghurair University, Dubai, United Arab Emirates
}

Received May 18, 2021; Revised July 14; Accepted July 29, 2021

\section{Cite This Paper in the following Citation Styles}

(a): [1] Gul Ahmed Jokhio, Yasmeen Gul, Abid Abu-Tair, "Using Epoxy Resin as Partial Cement Replacement in Concrete with Silica Sand as Fine Aggregate," Civil Engineering and Architecture, Vol. 9, No. 5, pp. 1513 - 1529, 2021. DOI: 10.13189/cea.2021.090523.

(b): Gul Ahmed Jokhio, Yasmeen Gul, Abid Abu-Tair (2021). Using Epoxy Resin as Partial Cement Replacement in Concrete with Silica Sand as Fine Aggregate. Civil Engineering and Architecture, 9(5), 1513 - 1529. DOI: 10.13189/cea.2021.090523.

Copyright $\bigcirc 2021$ by authors, all rights reserved. Authors agree that this article remains permanently open access under the terms of the Creative Commons Attribution License 4.0 International License

\begin{abstract}
Plain concrete has low tensile strength, therefore, it is reinforced with steel for structural use. Both the production of concrete and the manufacture of steel adversely affect the environment. Moreover, there is a new developing technology of 3D printing complex structural shapes, which makes it difficult to provide conventional steel reinforcement. This can be addressed partially by increasing the efficiency of concrete with respect to its properties; specifically, the tensile strength. Traditionally, silica fume is used for this purpose. This research is exploratory in nature in that it is breaking new ground by incorporating epoxy resin to partially replace cement in concrete with the fine aggregate partially replaced by silica. It was hypothesized that an increase, especially in the strength of concrete in tension, by the incorporation of epoxy resin will reduce the requirement of reinforcing steel, and thus making it a more suitable material for $3 \mathrm{D}$ printing of complex structural shapes. To test this hypothesis, a total of 144 concrete cubes and cylinders were made with the cement substituted by epoxy resin at the levels from 0 to $30 \%$ with $10 \%$ increments. The mechanical properties of these samples were measured after 3, 7, and 28 days. For lower values of cement replacement with epoxy, both the compressive and the tensile strength were reduced. However, when the epoxy proportion was increased, a positive change was noticed in the mechanical properties, especially the tensile strength. While the results obtained in the present study are not comprehensive, this research is a significant step towards further exploration in this area.
\end{abstract}

Keywords Epoxy Resin, Cement Replacement, Silica, Aggregate Replacement, Sustainable Concrete

\section{Introduction}

Conventional concrete made of cement, coarse and fine aggregates is a ubiquitously used material in the contemporary buildings [1]. The production of concrete is energy-intensive and also consumes a great amount of natural resources [2, 3, 4]. It is stipulated that the manufacture of cement alone is a significant participant in the emission of $\mathrm{CO}_{2}$ gases into the atmosphere $[5,6]$. Several attempts have been made over the recent years to introduce/promote sustainability of the construction industry with respect to the production of concrete $[7,8]$. A significant number of these attempts have been at incorporating agricultural and industrial wastes as partial or full replacement of concrete ingredients including cement, fine aggregate, and coarse aggregate $[9,10,11]$. The most recent notable contributions in this regard have been the use of palm oil fuel ash and fly ash in concrete in their nano particle sizes $[12,13]$. Other agricultural by-products such as palm oil clinker have also been used [14]. Some attempts have also been made at replacing concrete in less structurally intensive situations by alternative materials such as adobe $[15,16]$.

The manufacture of reinforcing steel is another energy 
intensive and environmentally expensive process $[17,18]$. Additionally, more often than not, it requires transportation over large distances, which adds to its adverse environmental impact [19, 20, 21]. The use of reinforcing steel in concrete is necessary because concrete is generally weak at taking tensile stresses $[22,23]$. To enhance the tensile capacity of concrete and to diminish the use of reinforcing steel, several alternative reinforcement strategies have been used over recent years [24, 25]. Some of these strategies include the use of steel wire mesh [26, $27,28]$, which additionally helps prevent excessive cracking; and the use of additional fibres such as kenaf [29, $30,31]$. Recently, there has been a growing trend in the use of polymers to modify cement mortar and cement concrete with research focusing on both the physical and the chemical characteristics of such a use of polymers $[32,33$, 34]. These recent developments towards improving the sustainability of reinforced concrete notwithstanding, there is still great potential for the use of alternative materials and techniques in order to make this industry more environment friendly. A novel technique in this regard is the use of epoxy resin as a binding material in concrete.

Epoxy resins are petroleum derived thermoset polymers $[35,36,37]$. These have been used to produce, among other applications, strong coatings [38, 39]. Some epoxy-bonded fibre-composite materials have also been used in structural applications such as; strengthening of RC beams [40], using epoxy-bonding GFRP plates to strengthen bridge beams [41], confining concrete with epoxy bonded fibre ropes [42], etc. However, the evidence found in the literature on the use of epoxy resin either as a binder replacement [43, 44, 45], or fine aggregate replacement for that matter, is scarce. Mostly, in the industry, polymer concrete is used for non-structural purposes, such as lining of the man-holes, sceptic tanks etc. due to its better resistance against adverse environmental conditions. A brief look at the recent developments in the use of polymers in concrete is presented below followed by an overview of the use of silica fume/nanosilica in concrete.

\section{Recent Developments in Polymer Concrete}

Conventionally, polymer concrete refers to a type of concrete in which a resin plays the role of the binder replacing cement [33]. While different types of resins have been used for this purpose; e.g. polyester, vinylester [46]; it has been reported that epoxy resin is the most efficient and, therefore, preferable despite its higher cost. Generally, to offset the high cost of epoxy resin, a filler is used. The advantages of epoxy resin over other resins include its relatively better thermal and mechanical properties as well as its durability aspects [47]. A quick scan of the available literature indicates that the use of other polyester and other resins diminished after the early 2000s in favour of epoxy resin. Several researchers have explored the properties of polymer concrete and attempted to develop design procedures and optimizations.

Ferdous et al. [33] investigated the optimal resin-to-filler and matrix-to-aggregate ratios from the point of view of durability and mechanical behaviour of the resulting concrete. The epoxy resin that they used was of the type diglycidyl ether of bisphenol-A (DGEBA), which has medium viscosity. They used a blend of 3 fillers i.e. fire retardant filler, micro-spheres, and fly ash. The coarse aggregate used was obtained in crushed form from a quarry and consisted of angular limestone. They concluded that mixes with the filler content of less than $40 \%$ showed significant segregation, which was averted at higher filler content. Higher filler content also reduced the negative effects of temperature. They also concluded that the tensile strength, flexural strength, and ductility of the resulting mix were decreased when matrix-to-aggregate ratio was lowered. They reported increased tensile as well as flexural strengths of the polymer concrete related to the conventional Portland cement concrete. In another study, Ferdous et al. [48] examined the influence of resin-to-filler ratio on the properties of epoxy polymer concrete matrix. The concluded that while the addition of the filler was helpful in controlling the temperature of the exothermic reaction between the resin and the hardener, excessive quantity of filler $(>60 \%)$ reduced the workability significantly. The addition of the filler also increased the density of the polymer matrix resulting in bigger voids in the matrix. It was reported that the filler helped increase flexural stiffness while the strength was dominated by the polymer and decreased with the increasing filler ratio.

Fernandez-Ruiz et al. [43] studied the behaviour of epoxy polymer concrete in compression both with, and without the hardener. They used siliceous sand as fine aggregate and gravel as coarse aggregate. The authors used Bisphenol A-type epoxy resin with and without the hardener to partially replace cement. They concluded that the performance of the epoxy with the hardener was better than that without the hardener. While the post-peak response of the epoxy polymer concrete was flatter and it showed greater ductility, both the flexural and the compressive strengths were reported to have dropped. When the epoxy resin was used with the hardener, the compressive strength was lower by approximately $14 \%$ at $10 \%$ epoxy, and approximately $29 \%$ at $15-20 \%$ epoxy in comparison to the control mix.

Jafari et al. [34] used NITOBOND-EP epoxy resin with a base/hardener ratio of $1.73: 1$ by weight for optimizing the mixture design of polymer concrete. They tested cylindrical specimens for uniaxial compression and splitting-tensile strength. While the researchers claimed that the optimal mixture design for the compressive, splitting-tensile, and flexural strengths was $14 \%$ polymer content and coarse aggregate size $9.5-19 \mathrm{~mm}$ tested under a temperature of $-15^{\circ} \mathrm{C}$, at the same time, they reported that, 
"the temperature had more significant effect on destructive test results compared to polymer content and coarse aggregate size". Jafari and Toufigh [49] also investigated the properties of rubberized polymer concrete. They used waste tyre rubber both in the form of chipped rubber to partially replace coarse aggregate and crumbed rubber to partially replace fine aggregate. They reported a reduction in the workability of the resulting mixes. The compressive strength was also significantly lower in case of rubberized specimens.

Gil-Martin et al. [44] investigated the cyclic behaviour of beam-column joints with epoxy resin as partial cement replacement. They used a multipurpose bi-component epoxy resin available with the commercial name of Sikafloor ${ }^{\circledR} 161$ to replace $15 \%$ of the cement in the mix. They concluded that the use of epoxy resin as partial cement replacement reduced the compressive strength of the resulting concrete, however, the load carrying capacity of the specimen with epoxy resin was reported to be similar to that of the control.

A significant contribution was made by Shi-Cong and Chi-Sun [50] when they produced a polymer concrete by adding recycled glass aggregates, fly ash, and metakaolin. They used DGEBA epoxy resin and an aliphatic hardener. Recycled glass was used as the coarse aggregate whereas the fine aggregate consisted of recycled galss and fly ash, and, recycled glass and metakaolin. The authors compared the properties of the control, which consisted of polymer concrete with waste glass aggregates only with those of the concretes with fly ash and metakaolin, respectively. The concluded that the addition of fly ash and metakaolin enhances the mechanical properties of the resulting concrete, which has a potential to be produced at an industrial scale.

Jung, Roh, and Chang [51] reported that the polymer concrete was able to fully cure at a very fast rate. They used YD-128 epoxy and KH-891 hardener, both produced by KUKDO Chemical, Korea as the binder and conventional coarse and fine aggregates. The authors did not use any filler for the polymer matrix. While the flexural as well as compressive strengths of the polymer concrete at 6 hours of curing were higher compared to the ordinary Portland cement concrete at 28 days of curing, its elasticity modulus was significantly lower. Furthermore, the coefficient of thermal expansion of the polymer concrete was significantly higher, which raised the author's concerns about the serviceability of the polymer concrete. Because of the higher thermal expansion, it is also difficult to ensure the compatibility if different parts of a structure are constructed by different concretes, such as a part of a runway made originally with the conventional concrete being repaired by polymer concrete.

Agavriloaie et al. [52] used a different kind of polymer to produce epoxy polyurethane acryl concrete (EPUAC). They found the mechanical properties of this concrete to be comparable with the polyester resin concrete, whereas it offered greater thermal comfort in terms of its insulation properties.

The mechanical and physical properties of epoxy polymer concrete subjected to higher temperature were studied by Oussama et al. [53]. They used polymer along with cement in the ratios of $6 \%, 9 \%, 13 \%$, and $16 \%$. They found out that the polymer concrete with $13 \%$ of polymer resulted in the best mechanical behaviour, with compressive and flexural strengths higher than the conventional cement concrete. However, at elevated temperatures up to $250^{\circ} \mathrm{C}$, while the two strengths of the conventional concrete remained virtually constant, those for the polymer concrete dropped significantly but still remained comparable to the ordinary cement concrete at temperatures up to $225^{\circ} \mathrm{C}$.

The quick scan of literature as presented above reveals that the technology of polymer concrete is yet nascent and needs much investigation before it graduates into a standard practice. It can be cautiously concluded that epoxy resin when used in conjunction with a hardener performs better as a binder in concrete compared to other polymers. Polymer concrete with only the polymer as the binding agent shows enhanced compressive as well as flexural strength, however, its modulus of elasticity is lower. Furthermore, polymer concrete, as is the case with polymers in general, is highly susceptible to rising temperatures and tends to lose its strength at elevated temperatures. Another issue to be considered in regards to the polymer concrete, especially when using epoxy resin, is its relatively high cost. Some researchers have tried a workaround by adding some filler in the polymer matrix. This strategy helps reduce the cost as well as increase the modulus of elasticity. However, the addition of a filler material in the polymer matrix reduces the compressive and flexural strengths of the resulting concrete. Among the various fillers used in polymer concrete, fly-ash and the ordinary Portland cement are the ones most commonly used. Researchers have also used alternate aggregates such as waste glass and ground tyre rubber as alternate aggregates in polymer concrete.

\section{Use of Silica in Concrete}

Traditionally silica fume [54], and more recently nano-silica [55] has been used as a filler in concrete mostly with cement, and in a very few cases, polymer, as the binder. Silica, in any of its forms, is primarily used in concrete due to its pozzolanic properties that help enhance the mechanical properties of the resulting concrete [56].

Binici and Aksogan [57] studied the durability of concrete partially/full replacing fine aggregate with silica sand at the replacement levels of $10 \%, 20 \%, 30 \%, 40 \%$, $50 \%$, and $100 \%$. They used standard crushed stone as the coarse aggregate. They reported that the unit weight of silica sand was higher than the conventional fine 
aggregates while its water absorption was lower. The capillary permeability coefficients for all levels of silica sand replacement were lower than the control, reduced by $10 \%, 25 \%, 40 \%, 55 \%, 60 \%$, and $65 \%$, respectively. The 28-day compressive strength was also reported to be higher for all the silica sand replacement levels ranging from $13 \%$ increase for $10 \%$ replacement level to $42 \%$ increase for $100 \%$ replacement level.

Mazloom, Ramezanianpour, and Brooks [54] investigated the short- and long-term mechanical properties of high-strength concrete containing different levels of silica fume ranging from 0 to $15 \%$. They reported that the compressive strength and the secant modulus increased at the cost of reduced workability with the increase in the silica fume proportion. While the proportion of silica fume did not affect the total shrinkage, it increased the autogenous shrinkage. They also stated that the basic creep of concrete was lower with the increasing proportion of silica fume.

Murthi et al. [58] used silica mineral waste, terming it as eco sand, as aggregate in their effort to produce environment friendly high strength concrete. They reported that the strength properties were boosted with the incorporation of silica mineral waste, whereas, the slump and compacting factors were low in all the concrete mixes. The optimum level of the replacement of the conventional fine aggregate with silica mineral waste was determined to be at $25 \%$.

Said et al. [55] studied the properties of concrete after incorporating nanosilica with and without fly ash as partial binder replacement. They reported that the specimen with $6 \%$ nanosilica had approximately $25 \%$ higher compressive strength and approximately $30 \%$ higher tensile strength than the control specimens. When $30 \%$ of cement was replaced with fly ash, both the compressive and tensile strength were reduced, however, adding nanosilica still produced the similar effects on compressive strength. The tensile strength was optimal at 3\% nanosilica only and it dropped slightly at $6 \%$ nanocilica.

$\mathrm{Du}, \mathrm{Du}$, and Liu [59] evaluated the durability performance of concrete containing nanosilica at $0.3 \%$ and $0.9 \%$ replacement levels. They reported that the microstructure of the resulting concrete became homogeneous with a reduced porosity due to nano-filler effect and the pozzolanic reaction provided by nanosilica. They reported increased compressive strength at early age as well as resistance against water and chloride ions for concrete containing nanosilica, even at the lower $0.3 \%$ amount.

Xie et al. [60] studied the coupling effects on the fracture behaviour of concrete using steel-fibre recycled aggregate. They used silica fume in the concrete mixture according to the Chinese standard as $10 \%$ cement replacement and, secondly, as additional ingredient equal to $3 \%$ of the cement mass. Sand was partially replaced by rubber at the volumetric fractions of up to $20 \%$ with $5 \%$ increments. They reported that while the addition of silica fume increased the compressive strength of concrete with steel fibres by about $44 \%$ as $10 \%$ cement replacement and by about $31 \%$ as $3 \%$ additional ingredient, the addition of rubber and the recycled aggregates had the opposite effect. As a general conclusion, it could be claimed that recycled aggregate concrete with $10 \%$ cement replaced by silica fume but without any rubber content was at par with new aggregate concrete without silica fume.

Guo et al. [61] attempted to produce sustainable self-compacting concrete with recycled aggregate and fly ash, slag, and silica fume as partial binder replacements. They tested mechanical as well as durability properties. They reported that the use of recycled aggregate reduced the mechanical properties, which was compensated when the binder replacements including silica fume were used. Similar behaviour of recycled aggregates and binder replacements was noted towards durability properties such as dry shrinkage. While the authors did not explicitly compare the performance of the three binder replacements i.e. fly ash, slag, and silica fume; looking at the results, it can be easily seen that silica fume performed better compared to the other two.

In order to reduce restrained shrinkage and compensate the loss of strength in cementitious mortars, Lefever et al. [62] used nanosilica along with superabsorbent polymers. The superabsorbent polymers that they used are copolymers of acrylamide and sodium acrylate. The nanosilica used was a type of colloidal silica. They observed that at initial stages, the mix containing both the superabsorbent polymers and nanosilica showed higher compressive strength but at 28 days, while all the mixes gained strength, the mix containing only nanosilica gained the most and reached about $90 \mathrm{MPa}$. The mix with only superabsorbent polymers started losing compressive strength after 28 days from about $73 \mathrm{MPa}$ to $71 \mathrm{MPa}$ at 90 days. A similar behaviour was observed in terms of flexural strength except that at 28 days, the mix with only the polymers showed the greatest strength at an average of 9 $\mathrm{MPa}$.

Keerio et al. [63] investigated the properties of the resulting concrete when they used silica fume to partially replace the binder and waste glass to partially replace fine aggregate. They replaced up to $15 \%$ of cement by silica fume with the increments of $5 \%$ and up to $40 \%$ of fine aggregate with waste glass with the increments of $10 \%$. They reported a significant loss in the workability as well as water absorption of the resulting mixture when silica fume and glass fine aggregate were used. The optimum replacement levels for silica fume and glass fine aggregate were reported as $10 \%$ and $30 \%$, respectively.

Verma et al. [64] used stone dust as partial fine aggregate replacement and silica fume as partial binder replacement in their attempt at producing sustainable concrete. They replaced up to $40 \%$ of fine aggregate with stone dust. After finding out that the optimal replacement level for stone dust is $30 \%$, the authors used that proportion and replaced the binder with silica fume at 5, 10, and 15\% 
replacement levels. The optimum replacement levels were thus identified as $30 \%$ stone dust replacing the fine aggregate and $10 \%$ silica fume replacing the binder.

This brief look at the literature on the use of silica fume as well as nanosilica as binder replacement in concrete indicates that it improves the mechanical behaviour of concrete. Therefore, silica has traditionally been used to produce high strength concrete in the form of silica fume or nanosilica. Conversely, in order to save precious resources and control he $\mathrm{CO} 2$ emissions, when the use of recycled/waste aggregates is attempted, it generally compromises the mechanical properties of the resulting mix. The strategy to compensate that by the combined use of silica fume/nano silica and the recycled/waste aggregates seems to be promising. It is, however, noted that few, if any, researchers have used silica as fine aggregate replacement recently. It would be worth investigating as to how does the use of silica as partial fine aggregate replacement affect the mechanical properties of the resulting mix.

The present study, therefore, aims to test the hypothesis that including epoxy resin as a binder replacement will increase the tensile strength of silica concrete for structural purposes, especially for $3 \mathrm{D}$ printing of structures. It is expected that such an increase in the tensile strength without significantly compromising on the compressive strength can potentially reduce the use of cement, but more importantly, the reinforcing steel. The above hypothesis was tested experimentally. An initial and brief report on the findings of this study was presented elsewhere [65]. The present paper reports the study and its findings in entirety along with a contextual literature review and the ensuing discussion.

\section{Methodology}

This is an experimental research in which cube specimens were examined for compressive strength and cylinder specimens were used to measure splitting-tensile strength; with the purpose of determining the effects of the use of epoxy resin along with silica sand in concrete. The description of the materials used, the specimens prepared and the tests conducted are as follows.

\subsection{Materials}

The materials used in this investigation consisted of Ordinary Portland Cement (OPC), common river sand as fine aggregate, ordinary crushed stone as coarse aggregate, epoxy resin as partial binder replacement, and silica sand as partial fine aggregate replacement. The chemical as well as physical properties of OPC are well known and quoted several times in literature. The chemical analysis of the silica sand revealed the presence of the various metal oxides in its composition as presented in table 1 along with that of the river sand used in the present study.

Table 1. Metal oxide values in the two types of sand used

\begin{tabular}{ccc}
\hline Metal oxide & \%Wt in silica sand & $\% \mathrm{Wt}$ in river sand used \\
\hline $\mathrm{SiO} 2$ & 93.2 & 56.23 \\
$\mathrm{CaO}$ & 0.9 & 2.82 \\
$\mathrm{MgO}$ & 0.6 & 1.97 \\
$\mathrm{~A} 12 \mathrm{O} 3$ & 0.8 & 19.43 \\
$\mathrm{Fe} 2 \mathrm{O} 3$ & 0.7 & 4.65 \\
$\mathrm{~K} 2 \mathrm{O}$ & 0.5 & - \\
Loss on Ignition & 3.3 & 14.9 \\
\hline
\end{tabular}

The sieve analysis was carried out for the gradation of the common river sand as well as the silica sand used in these experiments. The gradation charts for the common river sand and the silica sand are presented in figure 1. Two sizes of coarse aggregate i.e. $10 \mathrm{~mm}$ and $20 \mathrm{~mm}$ were used in equal proportion.

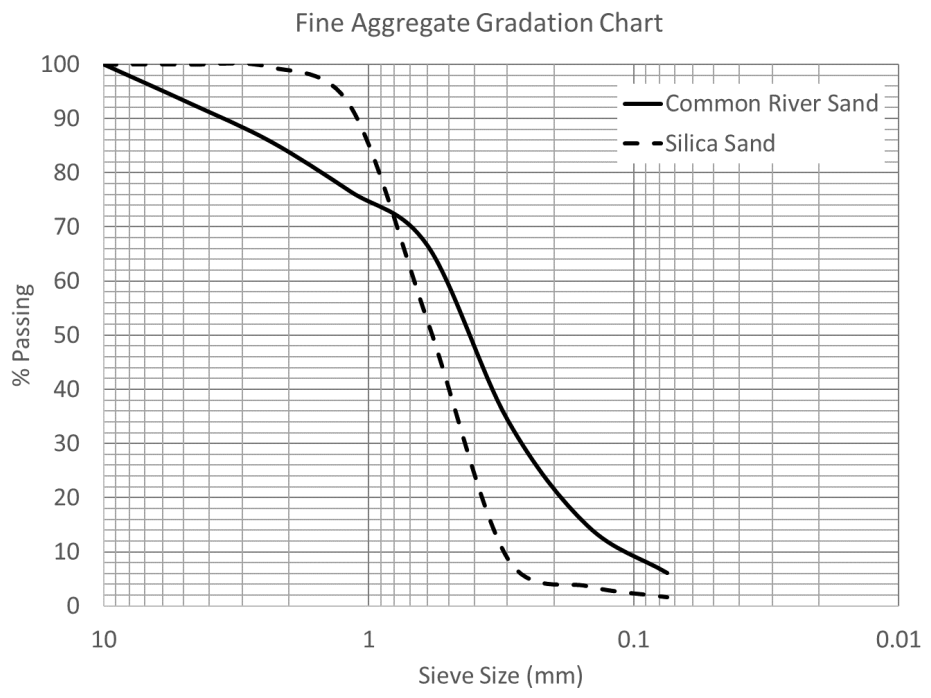

Figure 1. The gradation chart for the river sand and silica sand used as fine aggregate in this study 
Table 2. Details of the mix proportions used for sample preparation (All quantities are in $\mathrm{g} / \mathrm{kg}$ ).

\begin{tabular}{|c|c|c|c|c|}
\hline Mix Name & Cement & Epoxy Resin & Common River Sand & Silica Sand \\
\hline SOEO & 137 & 0 & 343 & 0 \\
\hline$S 25 E 0$ & 137 & 0 & 257 & 86 \\
\hline S50E0 & 137 & 0 & 172 & 171 \\
\hline$S 75 E 0$ & 137 & 0 & 86 & 257 \\
\hline S100E0 & 137 & 0 & 0 & 343 \\
\hline S100E10 & 123 & 14 & 0 & 343 \\
\hline S100E20 & 110 & 27 & 0 & 343 \\
\hline S100E30 & 96 & 41 & 0 & 343 \\
\hline
\end{tabular}

Note: $88 \mathrm{~g}$ of water, $144 \mathrm{~g}$ of $10 \mathrm{~mm}$ size coarse aggregate, and $288 \mathrm{~g}$ of $20 \mathrm{~mm}$ size coarse aggregate were used per $\mathrm{kg}$ of mix for all proportions

The epoxy resin used in this study was the Crystal Clear

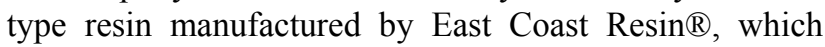
came in two parts; A, and B. The two parts were mixed in equal volume, as recommended by the manufacturer, for use in this study. It is worth noting here that other brands of such resin are available in the market and that this research did not intend to test any particular brand. The resin used in this study was obtained from the usual supplier of the laboratory materials without informing the manufacturer. It is assumed that the performance of any other brand of resin with the similar chemical composition and physical characteristics will also be the same as the one used here.

\subsection{Mix Proportions and the Preparation of Specimens}

A total number of 144 specimens were prepared. Out of the 144,72 were cubes with the side dimension of $100 \mathrm{~mm}$ and the other 72 were $300 \mathrm{~mm}$ long cylinders with a 150 $\mathrm{mm}$ diameter. The cubes were tested for the compressive strength whereas the cylinders were used to measure the splitting tensile strength. Besides the control, 4 proportions of the fine aggregate replacement with silica sand were used i.e. $25 \%, 50 \%, 75 \%$, and $100 \%$. Moreover, 3 proportions $(10 \%, 20 \%, 30 \%)$ of the replacement of binder with epoxy resin were used. The water-to-binder ratio $(0.64)$ and the proportion of each of the two sizes of coarse aggregate $(14.4 \% 10 \mathrm{~mm}$ size, and $28.8 \% 20 \mathrm{~mm}$ size) were kept constant for all the mix proportions. The water/binder ratio was kept relatively high with the aim of attaining the required workability without the use of any plasticizer. Since the objective of the present experimental program was to make a comparison between the strengths rather than achieving a high strength, it was deemed more appropriate to remove a potential further parameter in the form of an admixture. The nomenclature used for the resulting 8 mixes and the relevant aggregate proportions are given in table 2. For each one of these 8 mixes, 18 specimens i.e. 9 cylinders and 9 cubes were prepared. For each proportion under investigation, 3 cylinders and 3 cubes each were tested after 3, 7, and 28 days after casting.

The concrete mixes were produced using a concrete mixer. The ingredients except water and epoxy resin were first dry-mixed in the appropriate proportions to obtain a homogenous mix. This was followed by the addition of water gradually until a homogenous paste was obtained. The two parts of the epoxy resin were mixed at this stage and added to the concrete mix. Once the epoxy resin was added and mixed well, the concrete was swiftly poured into moulds. In order to make sure there were no voids inside the specimens, a mechanized vibrating tray was used. All the specimens were demoulded 24 hours after pouring and placed in a water tank at room temperature (about $25^{\circ} \mathrm{C}$ ) at a depth of about 1 meter for wet curing until the test day.

\subsection{Tests Conducted}

The testing methods used in the present study consisted of the compressive strength test as per ASTM C39 and the tensile splitting test as per ASTM 496. The details of the testing methods used have been provided in the following subsections:

\subsubsection{Compressive Strength Test}

The compressive strength of the cubic specimens was measured using the Universal Testing Machine by adopting the ASTM C39 testing standard. The compressive load was applied to the specimens at a rate of $0.25 \mathrm{MPa}$ per second until failure. Figure 2 shows a specimen under compressive strength test.

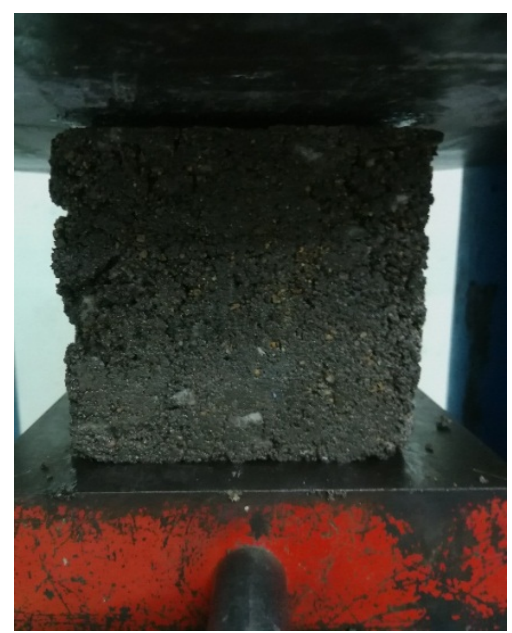

Figure 2. A cubic specimen under compressive strength test. 


\subsubsection{Splitting Tensile Strength Test}

The splitting tensile strength of the cylinder specimens was also measured using the Universal Testing Machine. For this purpose, the ASTM C496 testing standard was adopted. The standard recommends a load rate of 0.7 to 1.4 MPa per minutes. In the present study, a load rate of about $1 \mathrm{MPa}$ per minute was used until the specimen failed. Figure 3 shows a specimen being subjected to the splitting tensile strength test.

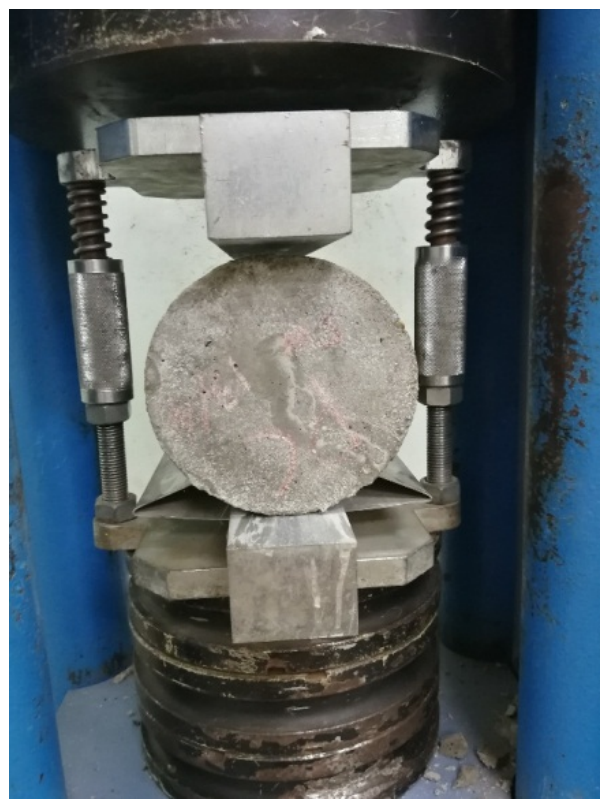

Figure 3. A cylinder specimen under splitting tensile strength test

\section{Results and Discussion}

\subsection{The Effects of Silica Sand as Fine Aggregate Replacement}

\subsubsection{On Compressive Strength}

In view of the positive influence of silica fume/nanosilica on the behaviour of concrete as reported in the literature briefly reviewed above, it was expected that the addition of silica sand as partial/full replacement of fine aggregate would have a similar effect. The results obtained in this study, in the limit, validate this hypothesis. Table 3 presents the results of the compressive strength test with varying proportions of silica sand after 3, 7, and 28 days. This is followed by a single factor analysis of variance (ANOVA) for the effect of silica sand at 3, 7, and 28 days of curing age as presented in Table 4. The P-value of 0.0084 and the $F$ value of 6.32 against an Fcrit value of 3.48 indicate that the inclusion of silica as fine aggregate replacement has a significant effect on the compressive strength of concrete at 3 days of curing age. For the 7 days of curing age, the P-value is 0.000194 and the $\mathrm{F}$ value is 16.82, which show that the effect of silica sand has become more significant as the curing age increases. Continuing to 28 days of curing age, the effect of silica sand remains significant with a P-value of 0.0008 and an $F$ value of 12.05 . The average values of compressive strength for the 3 curing ages and the various replacement levels of silica sand have been plotted as in Figure 4. Figure 5 presents the visual representation of the fitting of linear models for various proportions of fine aggregate replaced by silica sand at different curing ages.

Table 3. Results of the compressive strength test for various proportions of silica sand (All strength values are in MPa).

\begin{tabular}{c|ccc|ccc|ccc}
\hline \multirow{2}{*}{$\begin{array}{c}\text { Mix } \\
\text { Name }\end{array}$} & \multicolumn{3}{|c|}{ 3 Days } & \multicolumn{3}{c|}{ 7 Days } & \multicolumn{3}{c}{ 28 Days } \\
\cline { 2 - 22 } & Avg. & $\begin{array}{c}\text { Std. } \\
\text { Dev. }\end{array}$ & \% Increase & Avg. & Std. Dev. & \% Increase & Avg. & $\begin{array}{c}\text { Std. } \\
\text { Dev. }\end{array}$ & \% Increase \\
\hline S0E0 & 13.11 & 0.012 & - & 16.55 & 0.675 & - & 25.95 & 0.57 & - \\
S25E0 & 14.15 & 0.325 & 7.93 & 17.76 & 0.11 & 7.31 & 27.57 & 0.63 & 6.24 \\
S50E0 & 14.92 & 1.86 & 13.81 & 18.94 & 1.32 & 14.44 & 29.4 & 2.43 & 13.29 \\
S75E0 & 15.7 & 0.365 & 19.76 & 19.91 & 0.39 & 20.3 & 30.92 & 0.65 & 19.15 \\
S100E0 & 16.37 & 0.42 & 24.87 & 20.83 & 0.46 & 25.86 & 32.24 & 0.95 & 24.24 \\
\hline
\end{tabular}

Table 4. Single factor ANOVA for compressive strength test results for various proportions of silica sand.

\begin{tabular}{c|ccccccc}
\hline Curing Age & Source of Variation & SS & df & MS & F & P-value & F crit \\
\hline \multirow{3}{*}{ 3 Days } & Between Groups & 19.64 & 4 & 4.91 & 6.32 & 0.0084 & 3.48 \\
& Within Groups & 7.77 & 10 & 0.777 & & & \\
& Total & 27.41 & 14 & & & & \\
& Between Groups & 34.55 & 4 & 8.64 & 16.82 & 0.000194 \\
7 Days & Within Groups & 5.14 & 10 & 0.514 & & & 3.48 \\
& Total & 39.69 & 14 & & & \\
\hline \multirow{3}{*}{ 28 Days } & Between Groups & 76.43 & 4 & 19.11 & 12.05 & 0.0008 \\
& Within Groups & 15.86 & 10 & 1.586 & & & \\
\hline
\end{tabular}




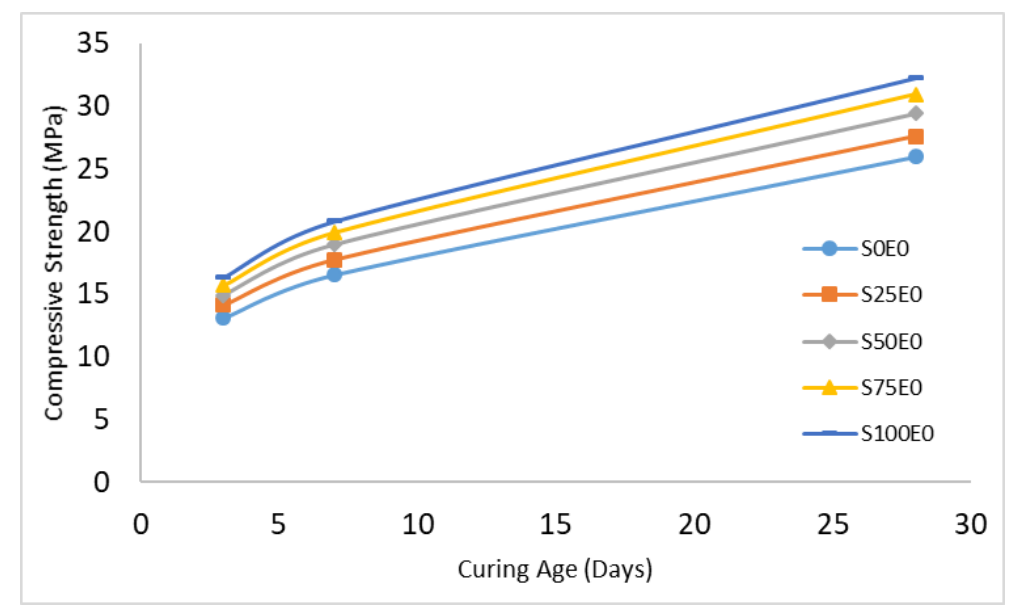

Figure 4. Average compressive strength test results for various proportions of silica sand.

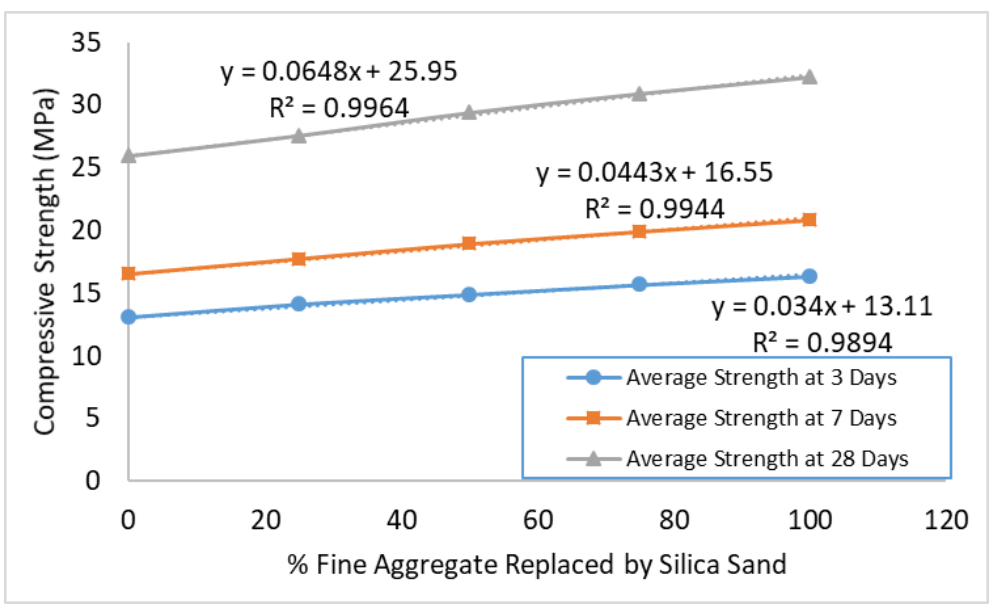

Figure 5. The compressive strength linear model fit for fine aggregate replacement with silica sand at various curing ages

It is noted that the y-intercepts for the linear models, displayed in Figure 5, have been set as the average strength of the mix S0E0 at the respective curing ages. With the statistical significance established through ANOVA results presented in Table 4, it can be stated with confidence that the replacement of fine aggregate with silica sand produces better compressive strength of concrete with the effect becoming more prominent as the curing age advances. The percent increase in the average compressive strength for each silica sand replacement level for the different curing ages can be read from Table 3. At 28 days, the $\%$ increased compressive strength at silica sand replacement levels of $25 \%, 50 \%, 75 \%$, and $100 \%$ was approximately $6 \%, 13 \%$, $19 \%$, and $24 \%$, respectively. These outcomes are in accord with prevailing literature, e.g. [58].

\subsubsection{On Splitting Tensile Strength}

Generally, the splitting tensile strength in concrete is much smaller than the compressive strength, which is true for the results obtained in this study as well. However, in terms of the influence of silica sand as fine aggregate replacement, the results follow, in the limit, a similar trend as the compressive strength with the effects being comparatively less significant. Table 5 presents the splitting tensile strength test results for the cylinder specimens with varying proportions of silica sand replacement at the different curing ages. This is followed by a single factor analysis of variance (ANOVA) for the effect of silica sand at 3, 7, and 28 days curing age as presented in Table 6. The P-value of 0.044 and the $\mathrm{F}$ value of 3.65 against an Fcrit value of 3.48 indicate that the inclusion of silica as fine aggregate replacement has a slightly significant effect on the splitting tensile strength of concrete at 3 days of curing age. For the 7 days of curing age, the $\mathrm{P}$-value is 0.045 and the $\mathrm{F}$ value is 3.62 , which show that the effect of silica sand remains marginally significant as the curing age increases. Continuing to 28 days of curing age, the effect of silica sand is relatively more significant with a P-value of 0.016 and an F value of 5.14. The average values of splitting tensile strength for the 3 curing ages and the various replacement levels of silica sand have been plotted as in Figure 6. Figure 7 presents the visual representation of the fitting of linear models for various proportions of fine aggregate replaced by silica sand at different curing ages. 
Table 5. Splitting tensile strength test results for various proportions of silica sand (All strength values are in MPa).

\begin{tabular}{|c|c|c|c|c|c|c|c|c|c|}
\hline \multirow{2}{*}{$\begin{array}{c}\text { Mix } \\
\text { Name }\end{array}$} & \multicolumn{3}{|c|}{3 Days } & \multicolumn{3}{|c|}{7 Days } & \multicolumn{3}{|c|}{28 Days } \\
\hline & Avg. & Std. Dev. & $\begin{array}{c}\% \\
\text { Increase } \\
\end{array}$ & Avg. & Std. Dev. & $\begin{array}{c}\% \\
\text { Increase } \\
\end{array}$ & Avg. & Std. Dev. & $\begin{array}{c}\% \\
\text { Increase } \\
\end{array}$ \\
\hline SOE0 & 1.15 & 0.089 & - & 1.52 & 0.085 & - & 2.42 & 0.172 & - \\
\hline S25E0 & 1.18 & 0.05 & 2.9 & 1.56 & 0.086 & 3.08 & 2.56 & 0.137 & 5.64 \\
\hline S50E0 & 1.26 & 0.072 & 9.57 & 1.65 & 0.118 & 8.79 & 2.64 & 0.105 & 9.08 \\
\hline S75E0 & 1.32 & 0.075 & 14.78 & 1.72 & 0.05 & 13.62 & 2.81 & 0.112 & 15.82 \\
\hline S100E0 & 1.43 & 0.173 & 24.35 & 1.78 & 0.135 & 17.36 & 2.95 & 0.232 & 21.87 \\
\hline
\end{tabular}

Table 6. Single factor ANOVA for splitting tensile strength test results for various proportions of silica sand.

\begin{tabular}{c|ccccccc}
\hline Curing Age & Source of Variation & SS & df & MS & F & P-value & F crit \\
\hline \multirow{3}{*}{ 3 Days } & Between Groups & 0.1503 & 4 & 0.0376 & 3.6529 & 0.0439 & 3.48 \\
& Within Groups & 0.1029 & 10 & 0.0103 & & & \\
& Total & 0.2532 & 14 & & & & \\
& Between Groups & 0.1425 & 4 & 0.0356 & 3.6213 & 0.045 \\
7 Days & Within Groups & 0.0984 & 10 & 0.00984 & & 0.0164 \\
& Total & 0.2409 & 14 & & & 3.48 \\
& Between Groups & 0.517 & 4 & 0.1293 & 5.136 & & \\
\hline \multirow{3}{*}{ 28 Days } & Within Groups & 0.2517 & 10 & 0.0252 & & & \\
& Total & 0.7687 & 14 & & & & \\
& & & &
\end{tabular}

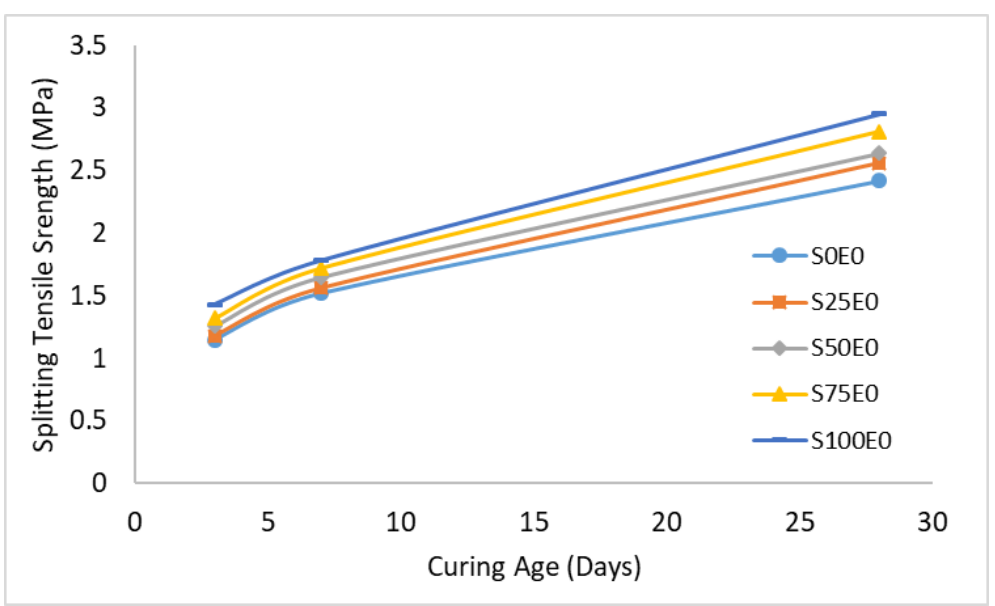

Figure 6. Average splitting tensile strength test results for various proportions of silica sand 


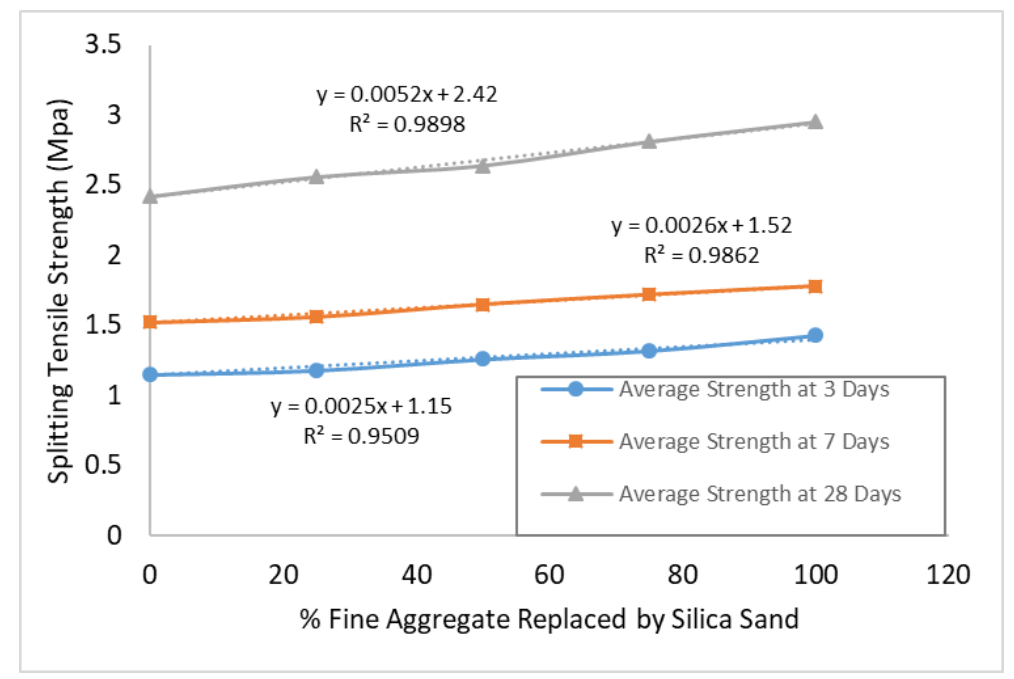

Figure 7. The splitting tensile strength linear model fit for fine aggregate replacement with silica sand at various curing ages

Similar to the compressive strength linear models, the $y$-intercepts for the splitting tensile strength linear models, displayed in Figure 7, have also been set as the average strength of the mix S0E0 at the respective curing ages. With the marginal statistical significance evaluated through ANOVA results presented in Table 6, it can be stated that the replacement of fine aggregate with silica sand increases the splitting tensile strength of concrete. The $\%$ escalation in the average splitting tensile strength for each silica sand replacement level for the different curing ages can be read from Table 5 . At 28 days of curing age, the $\%$ increases in the splitting tensile strength for silica sand replacement levels of $25 \%, 50 \%, 75 \%$, and $100 \%$ are approximately $6 \%, 9 \%, 16 \%$, and $22 \%$, respectively.

\subsection{The Effects of Epoxy Resin as Binder Replacement}

\subsubsection{On Compressive Strength}

The influence of utilizing epoxy resin to partially replace the binder is not as linear as that of the silica sand as fine aggregate replacement. This is in agreement with the brief literature review presented above. The average compressive strength test results for cube specimens at different levels of binder replacement with epoxy resin are presented in table 7. It was observed that the compressive strength of concrete dropped drastically when epoxy resin replaced $10 \%$ of the binder with the drop ranging from $68 \%$ to $75 \%$ for various curing ages. The strength continued to drop further as more epoxy resin replaced the binder with the greatest drop of approximately $79 \%$ was observed at 28 days of curing age at $20 \%$ binder replacement level. However, the concrete started regaining strength as further epoxy resin was added. 3 days after casting, a gain of $3.75 \%$ in compressive strength was noted for $30 \%$ binder replaced by epoxy resin. The regain didn't enter the positive range after 7 and 28 days post-casting. At 28 days of curing age, the strength remained approximately $32 \%$ below the control. The statistical significance of the effect of binder replacement by epoxy resin is evident from the single factor ANOVA as presented in Table 8. The P-values for 3, 7, and 28 days remain of the order of $10^{-9}$, $10^{-11}$, and $10^{-10}$, respectively; which indicate a very strong statistical significance. The $F$ values of 576,1614 , and 853 , for 3, 7, and 28 days of curing age, respectively; are also considerably larger than the Fcrit value of 4.066. The plots of the average compressive strength for various epoxy resin proportions are presented in Figure 8 with linear models fitted to the data. With the y-intercept being irrelevant here, the linear models show that the effect of curing age diminishes as epoxy resin is added. For all the proportions of epoxy resin, the slope of the linear model remains in the range of 0.08 to 0.17 , whereas the same for the control sample is 0.6. The same is evident from the trend in Figure 9 , where it can be observed that the difference between the strengths at different curing ages is considerably smaller for specimens with some portion of the binder replaced by epoxy resign. The trend apparently indicates that higher proportions of epoxy resin will result in greater concrete strength. 
Table 7. Compressive strength test results for various proportions of epoxy resin (All strength values are in MPa).

\begin{tabular}{c|ccc|ccc|ccc}
\hline \multirow{2}{*}{$\begin{array}{c}\text { Mix } \\
\text { Name }\end{array}$} & \multicolumn{3}{|c|}{ 3 Days } & \multicolumn{3}{c|}{ 7 Days } & \multicolumn{3}{c}{ 28 Days } \\
\cline { 2 - 10 } & Avg. & Std. Dev. & $\begin{array}{c}\text { \% } \\
\text { Change }\end{array}$ & Avg. & Std. Dev. & $\begin{array}{c}\text { \% } \\
\text { Change }\end{array}$ & Avg. & Std. Dev. & $\begin{array}{c}\text { \% } \\
\text { Change }\end{array}$ \\
\hline S100E0 & 16.37 & 0.42 & - & 20.83 & 0.46 & - & 32.24 & 0.95 & - \\
S100E10 & 5.13 & 0.664 & -68.65 & 6.58 & 0.5 & -68.43 & 7.94 & 0.73 & -75.39 \\
S100E20 & 4.35 & 0.33 & -73.43 & 5.72 & 0.11 & -72.54 & 6.76 & 0.33 & -79.04 \\
S100E30 & 16.97 & 0.513 & 3.75 & 19.46 & 0.12 & -6.56 & 21.95 & 0.73 & -31.92 \\
\hline
\end{tabular}

Table 8. Single factor ANOVA for compressive strength test results for various proportions of epoxy resin.

\begin{tabular}{|c|c|c|c|c|c|c|c|}
\hline Curing Age & Source of Variation & SS & df & MS & $\mathbf{F}$ & P-value & F crit \\
\hline \multirow{3}{*}{3 Days } & Between Groups & 429.06 & 3 & 143.02 & 575.76 & $1.11 \mathrm{E}-09$ & 4.066 \\
\hline & Within Groups & 1.987 & 8 & 0.2484 & & & \\
\hline & Total & 431.043 & 11 & & & & \\
\hline \multirow{3}{*}{7 Days } & Between Groups & 591.76 & 3 & 197.25 & 1614.49 & $1.82 \mathrm{E}-11$ & 4.066 \\
\hline & Within Groups & 0.977 & 8 & 0.122 & & & \\
\hline & Total & 592.74 & 11 & & & & \\
\hline \multirow{3}{*}{28 Days } & Between Groups & 1331.39 & 3 & 443.797 & 852.9 & $2.32 \mathrm{E}-10$ & 4.066 \\
\hline & Within Groups & 4.163 & 8 & 0.52 & & & \\
\hline & Total & 1335.55 & 11 & & & & \\
\hline
\end{tabular}

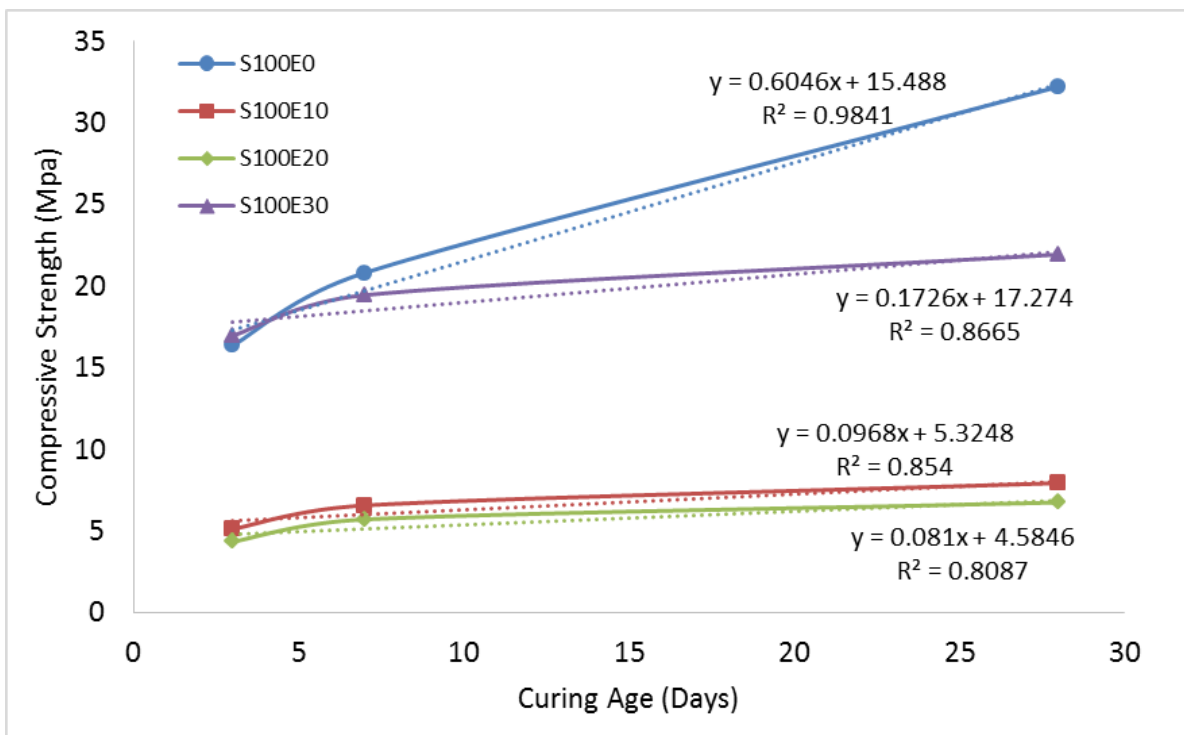

Figure 8. Average compressive strength test results for various proportions of epoxy resin at different curing ages along with the linear models fitted to the data 


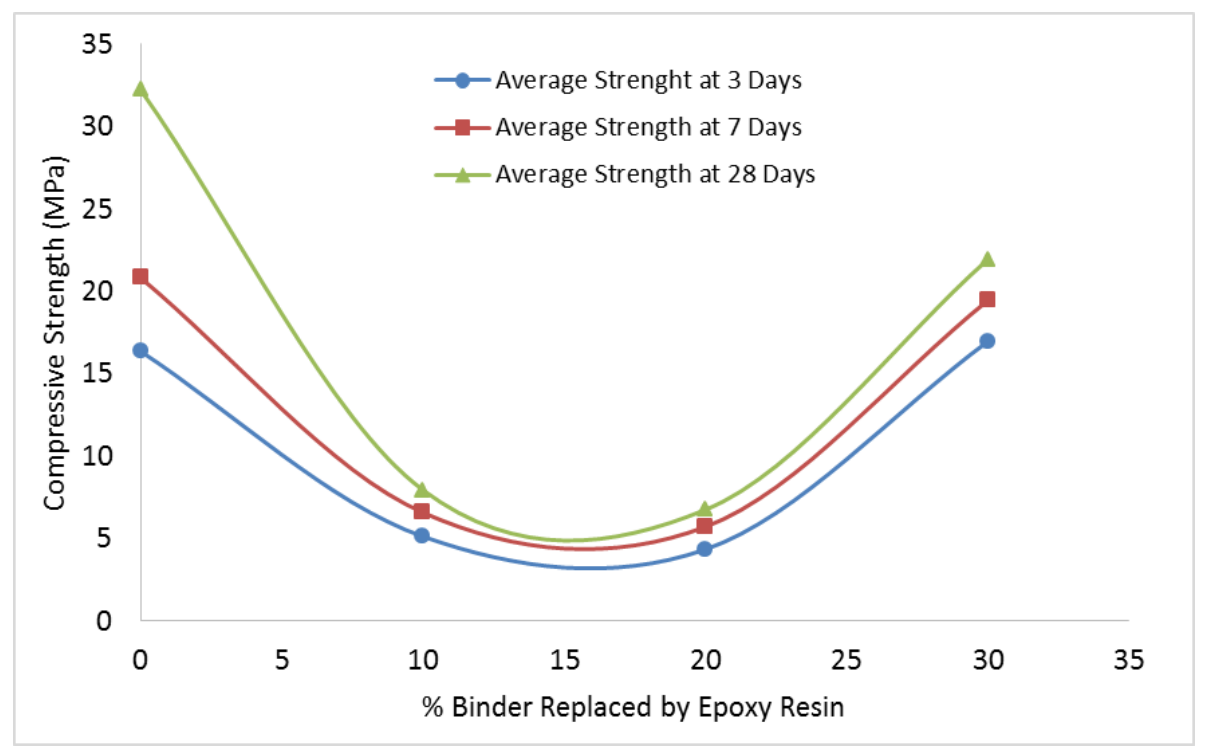

Figure 9. Average compressive strength test results for various proportions of epoxy resin

Figure 9 shows that the compressive strength drops as epoxy resin is added in lower portions. The average 28-day compressive strength for $10 \%$ epoxy resin is only approximately $25 \%$ of that with no epoxy resin. This further drops to approximately $21 \%$ when $20 \%$ epoxy resin was used. However, for epoxy resin proportion of $30 \%$, the compressive strength seems to have bounced back to reach approximately $68 \%$ of that of the control specimen. It is postulated that the addition of epoxy resin adversely affects the effectiveness of cement as a binder and the low amount of epoxy does not produce enough of its own binding force. For larger proportion, the increase in the compressive strength may be attributed to epoxy resin. This hypothesis, however, requires further investigation to be validated. In case this hypothesis is validated, it might be desirable to use a more environment friendly filler material along with epoxy resign instead of cement.

\subsubsection{On Splitting Tensile Strength}

The effects of the use of epoxy resin as partial binder replacement on splitting tensile strength are quite similar to those on the compressive strength. The average splitting tensile strength test results for cylinder specimens at different levels of binder replacement with epoxy resin are presented in Table 9. It was detected that the splitting tensile strength dropped drastically when epoxy resin replaced $10 \%$ of the binder with the drop ranging from $56 \%$ to $66 \%$ for various curing ages, with the greatest drop of approximately $66 \%$ at 7 days of curing age at $10 \%$ binder replacement level. Similar to the compressive strength, which continued to drop for $20 \%$ replacement level, the splitting tensile strength also continued to drop, which remained in the range of approximately $53 \%$ to $63 \%$ for $20 \%$ binder replacement level. The concrete continued regaining strength as further epoxy resin was added. A gain of approximately $14 \%, 11 \%$, and $4 \%$ in splitting tensile strength was noted for $30 \%$ binder replaced by epoxy resin at 3,7 and 28 days of curing age, respectively. The statistical significance of the effect of binder replacement by epoxy resin is evident from the single factor ANOVA as presented in Table 10. The P-values for 3, 7, and 28 days remain of the order of $10^{-6}$; which indicates a very strong statistical significance. The $F$ values of 33,63 , and 68 , for 3 , 7 , and 28 days of curing age, respectively; are also considerably larger than the Fcrit value of 4.066. The plots of the average splitting tensile strength for various epoxy resin proportions are presented in Figure 10 with linear models fitted to the data. The linear models show that the effect of curing age diminishes for lower binder replacement levels but it emerges again for 30\% replacement level. For the $10 \%$ and $20 \%$ proportions of epoxy resin, the slope of the linear model remains in approximately 0.03 , whereas the same for the $30 \%$ proportion and the control sample is approximately 0.06 . This result is by no means conclusive, however, it necessitates an investigation if epoxy resin continues to gain tensile strength over time. The trend depicted in Figure 11 apparently indicates that higher proportions of epoxy resin will result in greater concrete strength. While the difference in the splitting tensile strength at 3 days and 7 days diminishes for $10 \%$ and $20 \%$ binder replacement levels, it re-emerges at 28 days. This warrants further investigation, preferably with a larger range of binder replacement levels and filler materials other than cement. 
Table 9. Splitting tensile strength test results for various proportions of epoxy resin (All strength values are in MPa).

\begin{tabular}{c|ccc|ccc|ccc}
\hline \multirow{2}{*}{$\begin{array}{c}\text { Mix } \\
\text { Name }\end{array}$} & \multicolumn{3}{|c|}{ 3 Days } & \multicolumn{3}{c|}{ 7 Days } & \multicolumn{3}{c}{ 28 Days } \\
\cline { 2 - 21 } & Avg. & Std. Dev. & $\begin{array}{c}\text { \% } \\
\text { Change }\end{array}$ & Avg. & Std. Dev. & $\begin{array}{c}\text { \% } \\
\text { Change }\end{array}$ & Avg. & Std. Dev. & $\begin{array}{c}\text { \% } \\
\text { Change }\end{array}$ \\
\hline S100E0 & 1.43 & 0.173 & - & 1.78 & 0.135 & - & 2.95 & 0.232 & - \\
S100E10 & 0.571 & 0.147 & -60.1 & 0.61 & 0.22 & -65.65 & 1.28 & 0.18 & -56.72 \\
S100E20 & 0.675 & 0.172 & -52.82 & 0.663 & 0.152 & -62.75 & 1.39 & 0.194 & -52.9 \\
S100E30 & 1.64 & 0.149 & 14.38 & 1.979 & 0.102 & 11.18 & 3.06 & 0.205 & 3.56 \\
\hline
\end{tabular}

Table 10. Single factor ANOVA for splitting tensile strength test results for various proportions of epoxy resin.

\begin{tabular}{|c|c|c|c|c|c|c|c|}
\hline Curing Age & Source of Variation & SS & df & MS & $\mathbf{F}$ & P-value & $F$ crit \\
\hline \multirow{3}{*}{3 Days } & Between Groups & 2.565 & 3 & 0.855 & 33.002 & $7.45 \mathrm{E}-05$ & 4.066 \\
\hline & Within Groups & 0.207 & 8 & 0.026 & & & \\
\hline & Total & 2.772 & 11 & & & & \\
\hline \multirow{3}{*}{7 Days } & Between Groups & 4.69 & 3 & 1.56 & 63.07 & $6.555 \mathrm{E}-06$ & 4.066 \\
\hline & Within Groups & 0.198 & 8 & 0.025 & & & \\
\hline & Total & 4.892 & 11 & & & & \\
\hline \multirow{3}{*}{28 Days } & Between Groups & 8.42 & 3 & 2.81 & 67.64 & $5.015 \mathrm{E}-06$ & 4.066 \\
\hline & Within Groups & 0.332 & 8 & 0.0415 & & & \\
\hline & Total & 8.747 & 11 & & & & \\
\hline
\end{tabular}

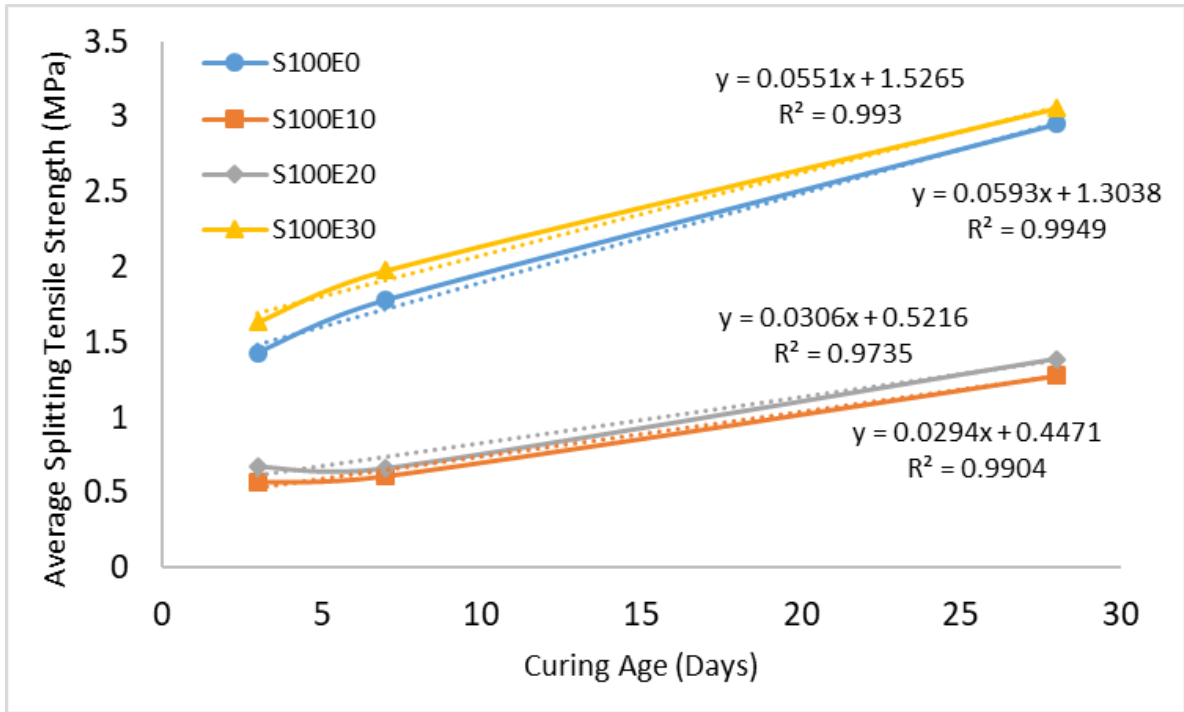

Figure 10. Average splitting tensile strength test results for various proportions of epoxy resin at different curing ages along with the linear models fitted to the data 


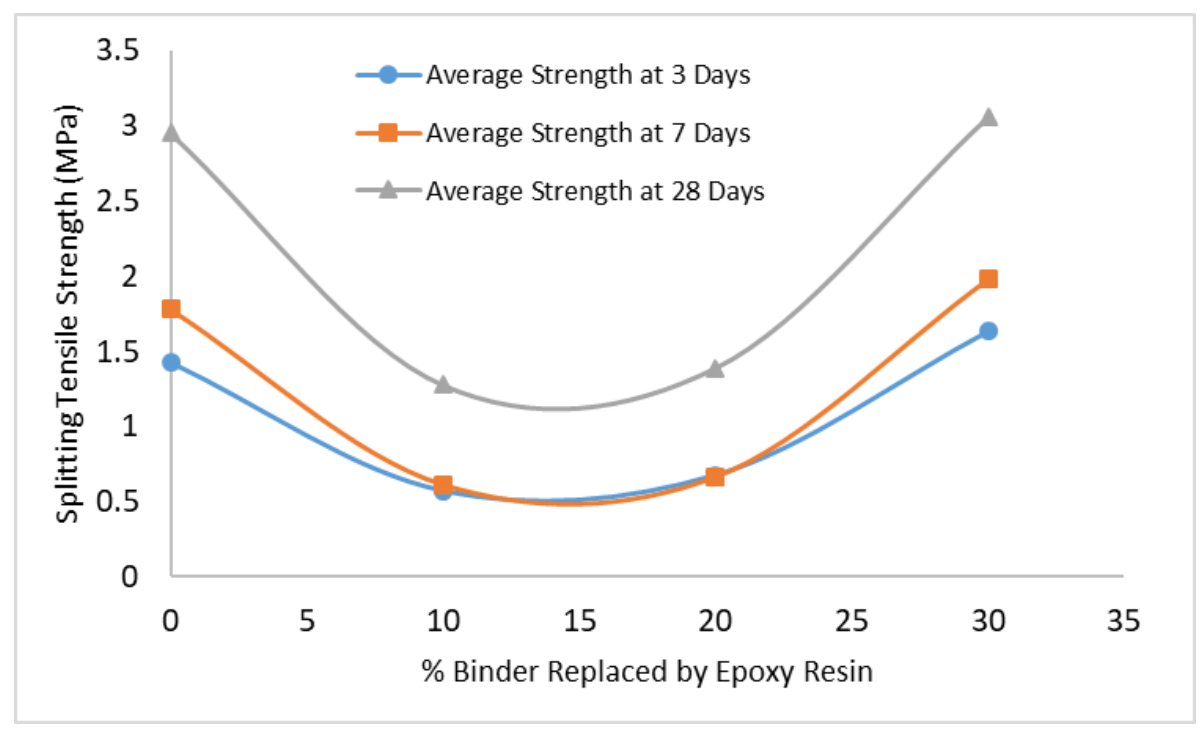

Figure 11. Average splitting tensile strength test results for various proportions of epoxy resin

A similar trend for the splitting tensile strength to that of the compressive strength can be observed in Figure 11. However, the drop in the splitting tensile strength is slightly less as it drops to about $43 \%$ and $47 \%$ of the splitting tensile strength of the control specimen for the epoxy proportions of $10 \%$ and $20 \%$, respectively. While the compressive strength for $20 \%$ epoxy proportion was less than that for $10 \%$, the splitting tensile strength is higher for $20 \%$ epoxy proportion. More importantly, the splitting tensile strength for the epoxy resin proportion of $30 \%$ went higher than the control specimen by about $4 \%$. It is postulated that a higher proportion of epoxy resin may further increase the splitting tensile strength of concrete. This inference is subjected to further investigation and validation.

\section{Conclusions}

The present study was exploratory in nature. The focus of the present research was on the effects of partial binder replacement with epoxy resin on the compressive and splitting tensile strength of concrete with silica sand as fine aggregate. Following conclusions have been drawn:

- The addition of silica sand as partial/full fine aggregate replacement in concrete enhances its compressive strength. After 28 days of curing, the \% increases in the compressive strength at different silica sand replacement levels of $25 \%, 50 \%, 75 \%$, and $100 \%$ were approximately $6 \%, 13 \%, 19 \%$, and $24 \%$, respectively. This behaviour is accompanied by strong statistical significance.

- When the silica sand replaces fine aggregate, it increases the splitting tensile strength of concrete, however, the statistical significance of this behaviour is marginal. At 28 days of curing age, the $\%$ increases in the splitting tensile strength for silica sand replacement levels of $25 \%, 50 \%, 75 \%$, and $100 \%$ are approximately $6 \%, 9 \%, 16 \%$, and $22 \%$, respectively.

- The compressive strength drops as epoxy resin is added in lower portions. The average 28-day compressive strength for $10 \%$ epoxy resin is only approximately $25 \%$ of that with no epoxy resin. This further drops to approximately $21 \%$ when $20 \%$ epoxy resin was used. However, for epoxy resin proportion of $30 \%$, the compressive strength reaches approximately $68 \%$ of that of the control specimen.

- The addition of epoxy resin adversely affects the effectiveness of cement as a binder and the low amount of epoxy does not produce enough of its own binding force. For larger proportion, the increase in the compressive strength may be attributed to epoxy resin.

- It might be desirable to use a more environment friendly filler material along with epoxy resin instead of cement.

- The splitting tensile strength dropped to about $43 \%$ and $47 \%$ of the splitting tensile strength of the control specimen with epoxy proportions of $10 \%$ and $20 \%$, respectively. However, the splitting tensile strength for the epoxy resin proportion of $30 \%$ was higher than the control specimen by about $4 \%$.

- A higher proportion of epoxy resin may further increase the splitting tensile strength of concrete.

The above conclusions are based on the small size of data observed in the present study. It is recommended that further investigation in this regard be carried out to ascertain the validity of these conclusions. It would especially be of interest to find out how the higher proportions than those used here may affect the compressive and the splitting tensile strength of concrete. Furthermore, the present study did not investigate the economic or environmental aspects of the use of epoxy 
resin in concrete. Future research in these areas is also recommended. The present study was partially inspired by the need for the development of sustainable materials suitable for the emerging 3D printing technology. For that purpose, not only the mechanical properties are important. Therefore, it is recommended that fresh properties as well as durability of the concrete incorporating epoxy resign and silica sand may be investigated.

\section{REFERENCES}

[1] M. S. Shetty and A. K. Jain, Concrete Technology: Theory and Practice, 8th ed., New Delhi: S Chand and Company Limited, 2019.

[2] H. M. Hamada, G. A. Jokhio, F. M. Yahaya, A. M. Humada and Y. Gul, "The present state of the use of Palm Oil Fuel Ash (POFA) in concrete," Construction and Building Materials, vol. 175, pp. 26-40, 2018.

[3] C. Bataille, M. Ahman, K. Neuhoff, L. J. Nilsson, M. Fischedick, S. Lechtenbohmer, B. Solano-Rodriquez, A. Denis-Ryan, S. Stiebert, H. Waisman, O. Sartor and S. Rahbar, "A review of technology and policy deep decarbonization pathway options for making energy-intensive industry production consistent with the Paris Agreement," Journal of Cleaner Production, vol. 187, pp. 960-973, 2018.

[4] M. S. Nasr, A. A. Shubbar, Z. A.-A. R. Abed and M. S. Ibrahim, "Properties of eco-friendly cement mortar contained recycled materials from different sources," Journal of Building Engineering, vol. 31, p. 101444, 2020.

[5] C. Meyer, "The greening of the concrete industry," Cement and Concrete Composites, vol. 31, no. 8, pp. 601-605, 2009.

[6] T. Du, J. Wang, H. Wang, X. Tian, Q. Yue and H. Tanikawa, "CO2 emissions from the Chinese cement sector: Analysis from both the supply and demand sides," Journal of Industrial Ecology, vol. 24, no. 4, pp. 923-934, 2020.

[7] S. Mindess, "Sustainability of concrete," in Developments in the Formulation and Reinforcement of Concrete (Second Edition), Woodhead Publishing, 2019, pp. 3-17.

[8] J. de Brito and R. Kurda, "The past and future of sustainable concrete: A critical review and new strategies on cement-based materials," Journal of Cleaner Production, vol. 281, p. 123558, 2021.

[9] B. H. Nagaratnam, M. E. Rahman, A. K. Mirasa, M. A. Mannan and S. O. Lame, "Workability and heat of hydration of self-compacting conrete incorporating agro-industrial waste," Journal of Cleaner Production, vol. 112, no. 1, pp. 882-894, 2016.

[10] W. Tangchirapat, T. Saeting, C. Jaturapitakkul, K. Kiattikomol and A. Siripanichgorn, "Use of waste ash from palm oil industry in conrete," Waste Management, vol. 27, no. 1, pp. 81-88, 2007.

[11] E. Khankahje, M. W. Hussin, J. Mirza, M. Rafieizonooz, M. R. Salim, H. C. Siong and M. N. Warid, "On blended cement and geopolymer concretes containing palm oil fuel ash," Materials \& Design, vol. 89, pp. 385-398, 2016.

[12] H. M. Hamada, G. A. Jokhio, F. M. Yahaya and A. M. Humada, "Applications of nano palm oil fuel ash and nano fly ash in concrete," IOP Conference series: Materials Science and Engineering, vol. 342, no. 1, p. 012068, 2018.

[13] H. M. Hamada, F. M. Yahaya, K. Muthusamy, G. A. Jokhio and A. M. Humada, "Fresh and hardened properties of palm oil clinker lightweight aggregate concrete incorporating Nano-palm oil fuel ash," Construction and Building Materials, vol. 214, pp. 344-354, 2019.

[14] H. M. Hamada, G. A. Jokhio, A. A. Al-Attar, F. M. Yahaya, K. Muthusamy, A. M. Humada and Y. Gul, "The use of plam oil clinker as a sustainable construction material: A review," Cement and Concrete Composites, vol. 106, p. 103447, 2020.

[15] G. A. Jokhio, F. M. Saad, Y. Gul, S. M. S. Mohsin and N. I. Ramli, "Uniaxial compression and tensile splitting tests on adobe with embedded steel wire reinforcement," Construction and Building Materials, vol. 176, pp. 383-393, July 2018.

[16] G. A. Jokhio, Y. M. Y. Al-Tawil, S. M. S. Mohsin, Y. Gul and N. I. Ramli, "Compressive and flexural tests on adobe samples reinforced with wire mesh," IOP Conference Series: Materials Science and Engineering, vol. 318, no. 1, p. $012030,2018$.

[17] I. Ahmad, M. S. Arif, I. I. Cheema, P. Thollander and M. A. Khan, "Drivers and Barriers for Efficient Energy Management Practices in Energy-Intensive Industries: A Case-Study of Iron and Steel Sector," Sustainability, vol. 12, no. 18 , p. 7703, 2020.

[18] S. Nabernegg, B. Bednar-Friedl, F. Wagner, T. Schinko, J. Cofala and Y. M. Clement, "The Development of Low Carbon Technologies in Energy Intensive Industries: A Macroeconomic Analysis for Europe, China and India," MDPI Energies, vol. 10, no. 3, p. 360, 2017.

[19] K. R. Erzaij and R. H. Ali, "The Effect of Desert Environment on the Cost of Construction Projects (Materials Transportation)," Applied Mechanics and Materials, vol. 897, pp. 152-156, 2020.

[20] E. Subiyanto, "Assessing Total Logistic Costs: Case Study During the Execution of Cement Projects in Indonesia," International Journal of Applied Logistics (IJAL), vol. 10, no. 2 , p. $17,2020$.

[21] B. Jiang, H. Li, L. Dong, Y. Wang and Y. Tao, "Cradle-to-Site Carbon Emissions Assessment of Prefabricated Rebar Cages for High-Rise Buildings in China," MDPI Sustainability, vol. 11, no. 1, p. 42, 2019.

[22] W. Zhong, J. Pan, J. Wang and C. Zhang, "Size effect in dynamic splitting tensile strength of concrete: Experimental investigation," Construction and Building Materials, p. $121449,2020$.

[23] S. Gurusideswar, A. Shukla, K. N. Jonnalagadda and P. Nanthagopalan, "Tensile strength and failure of ultra-high performance concrete (UHPC) composition over a wide range of strain rates," Construction and Building Materials, vol. 258, p. 119642, 2020.

[24] T. Cadenazzi, G. Dotelli, M. Rossini, S. Nolan and A. Nanni, 
"Cost and environmental analyses of reinforcement alternatives for a concrete bridge," Structure and Infrastructure Engineering, vol. 16, no. 4, pp. 787-802, 2020.

[25] N. Stoiber, M. Hammerl and B. Kromoser, "Cradle-to-gate life cycle assessment of CFRP reinforcement for concrete structures: Calculation basis and exemplary application," Journal of Cleaner Production, vol. 280, p. 123400, 2021.

[26] S. H. Lodi, S. F. A. Rafeeqi and G. A. Jokhio, "Ferrocement constitutive model and experimental validation," NED University Journal of Research, vol. 7, no. 2, pp. 137-151, 2010.

[27] J. Li, C. Wu, H. Hao and Y. Su, "Experimental and numerical study on steel wire mesh reinforced concrete slab under contact explosion," Materials \& Design, vol. 116, pp. 77-91, 2017.

[28] J. Liu, C. Wu, J. Li, Y. Su, R. Shao, Z. Liu and G. Chen, "Experimental and numerical study of reactive powder concrete reinforced with steel wire mesh against projectile penetration," International Journal of Impact Engineering, vol. 109, pp. 131-149, 2017.

[29] S. M. S. Mohsin, A. O. Baarimah and G. A. Jokhio, "Effect of kenaf fiber in reinforced concrete slab," IOP Conference Series: Materials Science and Engineering, vol. 342, no. 1, p. 012104, 2018.

[30] M. H. Baghban and R. Mahjoub, "Natual Kenaf Fiber and LC3 Binder for Sustainable Fiber-Reinforced Cementitious Composite: A Review," MDPI Applied Sciences, vol. 10, no. 1, p. 357, 2020.

[31] C. Zhou, L. Cai, Z. Chen and J. Li, "Effect of kenaf fiber on mechanical properties of high-strength cement composites," Construction and Building Materials, vol. 263, p. 121007, 2020.

[32] R. Wang, J. Li, T. Zhang and L. Czarnecki, "Chemical interaction between polymer and cement in polymer-cement concrete," Bulletin of the Polish Academy of Sciences. Technical Sciences., vol. 64, no. 4, pp. 785-792, 2016.

[33] W. Ferdous, A. Manalo, H. S. Wong, R. Abousnina, O. S. AlAjarmeh, Y. Zhuge and P. Schubel, "Optimal design for epoxy polymer concrete based on mechanical properties and durability aspects," Construction and Building Materials, vol. 232, p. 117229, 2020.

[34] K. Jafari, M. Tabatabaeian, A. Joshghani and T. Ozbakkaloglu, "Optimizing the mixture design of polymer concrete: An experimental investigation," Construction and Building Materials, vol. 167, pp. 185-196, 2018.

[35] C. A. May, Epoxy Resins: Chemistry and Technology, New York: MARCEL DEKKER, INC., 1988.

[36] S. Liu, V. S. Chevali, Z. Xu, D. Hui and H. Wang, “A review of extending performance of epoxy resins using carbon nanomaterials," Composites Part B: Engineering, vol. 136, pp. 197-214, 2018.

[37] Y. Wang, S. Chen, X. Chen, Y. Lu, M. Miao and D. Zhang, "Controllability of epoxy equivalent weight and performance of hyperbranched epoxy resins," Composites Part B: Engineering, vol. 160, pp. 615-625, 2019.
[38] H. Pulikkalparambil, S. Siengchin and J. Parameswaranpillai, "Corrosion protective self-healing epoxy resin coatings based on inhibitor and polymeric healing agents encapsulated in organic and inorganic micro and nanocontainers," Nano-Structures \& Nano-Objects, vol. 16, pp. 381-395, 2018.

[39] M. Zhong, Y. Zhang, X. Li and X. Wu, "Facile fabrication of durable superhydrophobic silica/epoxy resin coatings with compatible transparency and stability," Surface Coatings and Technology, vol. 347, pp. 191-198, 2018.

[40] T. C. Triantafillou and N. Plevris, "Strengthening of RC beams with epoxy-bonded fibre-composite materials," Materials and Structures, vol. 25, no. 4, pp. 201-211, 1992.

[41] M. R. Ehsani and H. Saadatmanesh, "Fiber composite plates for strengthening bridge beams," Composite Structures, vol. 15 , pp. 343-355, 1990.

[42] Q. Hussain, A. Ruangrassamee, S. Tangtermsirikul and P. Joyklad, "Behaviour of concrete confined with epoxy bonded fiber ropes under axial load," Construction and Building Materials, vol. 263, p. 120093, 2020.

[43] M. A. Fernandez-Ruiz, L. M. Gil-Martin, J. F. Carbonell-Marquez and E. Hernandez-Montes, "Epoxy resin and ground tyre rubber replacement for cement in concrete: Compressive behaviour and durability properties," Construction and Building Materials, vol. 173, pp. 49-57, 2018.

[44] L. M. Gil-Martin, A. E. Rodriguez-Suesca, M. A. Fernandez-Ruiz and E. Hernandez-Montes, "Cyclic behaviour of RC beam-column joints with epoxy resin and ground tire rubber as partial cement replacement," Construction and Building Materials, vol. 211, pp. 659-674, 2019.

[45] M. M. El-Hawary and A. Abdul-Jaleel, "Durability assessment of epoxy modified concrete," Construction and Building Materials, vol. 24, no. 8, pp. 1523-1528, 2010.

[46] W. Lokuge and T. Arvinthan, "Effect of fly ash on the behaviour of polymer concrete with different types of resin," Materials and Design, vol. 51, pp. 175-181, 2013.

[47] M. Loos, Carbon Nanotube Reinforced Polymers: CNT Polymer Science and Technology, UK: Elsevier, 2014.

[48] W. Ferdous, A. Manalo, T. Aravinthan and G. Van Erp, "Properties of epoxy polymer concrete matrix: Effect of resin-to-filler ratio and determination of optimal mix for composite railway sleepers," Construction and Building Materials, vol. 124, pp. 287-300, 2016.

[49] K. Jafari and V. Toufigh, "Experimental and analytical evaluation of rubberized polymer concrete," Construction and Building Materials, vol. 155, pp. 495-510, 2017.

[50] K. Shi-Cong and P. Chi-Sun, "A novel polymer concrete made with recycled glass aggregates, fly ash and metakaolin," Construction and Building Materials, vol. 41, pp. 146-151, 2013.

[51] K.-C. Jung, I.-T. Roh and S.-H. Chang, "Evaluation of mechanical properties of polymer concrete for the rapid repair of runways," Composites: part B, vol. 58, pp. $352-360,2014$

[52] L. Agavriloaie, S. Oprea, M. Barbuta and F. Luca, 
"Characterisation of polymer concrete with epoxy polyurethane acryl matrix," Construction and Building Materials, vol. 37, pp. 190-196, 2012.

[53] E. Oussama, G. Elhem, M. Valerie and B. O. Mongi, "Mechanical and physical properties of epoxy polymer concrete after exposure to temperatures up to $250 \mathrm{C}$," Construction and Building Materials, vol. 27, pp. 415-424, 2012.

[54] M. Mazloom, A. A. Ramezanianpour and J. J. Brooks, "Effect of silica fume on mechanical properties of high-strength concrete," Cement and Concrete Composites, vol. 26, no. 4, pp. 347-357, 2004.

[55] A. M. Said, M. S. Zeidan, M. T. Bassuoni and Y. Tian, "Properties of concrete incorporating nano-silica," Construction and Building Materials, vol. 36, pp. 838-844, 2012.

[56] L. P. Singh, S. R. Karade, S. K. Bhattacharyya, M. M. Yousuf and S. Ahalawat, "Beneficial role of nanosilica in cement based materials - A review," Construction and Building Materials, vol. 47, pp. 1069-1077, 2013.

[57] H. Binici and O. Aksogan, "Durability of concrete made with natural granular granite, silica sand and powders of waste marble and basalt as fine aggregate," Journal of Building Engineering, vol. 19, pp. 109-121, 2018.

[58] P. Murthi, P. Awoyera, P. Selvaraj, D. Dharsana and R. Gobinath, "Using silica mineral waste as aggregate in a green high strength concrete: workability, strength, failure mode, and morphology assessment," Australian Journal of Civil Engineering, vol. 16, no. 2, pp. 122-128, 2018.

[59] H. Du, S. Du and X. Liu, "Durability performances of concrete with nano-silica".

[60] J. Xie, J. Li, Z. Lu, Z. Li, C. Fang, L. Huang and L. Li,
"Combination effects of rubber and silica fume on the fracture behaviour of steel-fibre recycled aggregate concrete," Construction and Building Materials, vol. 203, pp. 164-173, 2019.

[61] Z. Guo, T. Jiang, J. Zhang, X. Kong, C. Chen and D. E. Lehman, "Mechanical and durability properties of sustainable self-compacting concrete with recycled concrete aggregate and fly ash, slag and silica fume," Construction and Building Materials, vol. 231, p. 117115 , 2020.

[62] G. Lefever, E. Tsangouri, D. Snoeck, D. G. Aggelis, N. D. Belie, S. V. Vlierberghe and D. V. Hemelrijck, "Combined use of superabsorbent polymers and nanosilica for reduction of restrained shrinkage and strength compensation in cementitious mortars," Construction and Building Materials, vol. 251, p. 118966, 2020.

[63] M. A. Keerio, S. A. Abbasi, A. Kumar, N. Bheel, K. U. Rehaman and M. Tashfeen, "Effect of silica fume as cementitious material and waste glass as fine aggregate replacement constituent on selected properties of concrete," Silicon, 2020.

[64] S. K. Verma, C. S. Singla, G. Nadda and R. Kumar, "Development of sustainable concrete using silica fume and stone dust," Materialstoday: Proceedings, vol. 32, no. 4, pp. $882-887,2020$

[65] G. A. Jokhio, Y. Gul, A. Abu-Tair and W. S. Gan, "The effects of epoxy resin as partial cement replacement on the mechanical properties of concrete," in Proceedings ICSBM 2019, Delft, 2019.

[66] D. Li, A. Toghroli, M. Shariati, F. Sajedi, D. T. Bui, P. Kianmehr, E. T. Mohamad and M. Khorami, "Application of polymer, silica-fume and crushed rubber in the production of pervious concrete," Smart Structures and Systems, vol. 23, no. 2, pp. 207-214, 2019. 